\title{
Almost 40 Years Knowing Prof. Rūsiņš Freivalds
}

\author{
Daina TAIMIN,A \\ Cornell University, Ithaca, NY 14853, USA \\ daina.taimina@cornell.edu
}

It was February of 1976. Some small group of American students was visiting Riga as tourists and it was arranged for them to meet students of the University of Latvia. I was an undergraduate then and I was suggested to be one of Latvian students to talk with the visitors. Before the meeting we had instructions not to touch politically sensitive topics or try to establish personal contacts with students to whom we talked. Each of us was to sit down with three or four foreign students and we were told that each mini group will also have some senior University member with good English language knowledge to assist us "in case some language problems appear" but they will not participate in our discussion. My conversation with American students was closely followed by a man in grey suit, blue shirt and dark blue tie with well used leather briefcase by his side. This is how I first met Rūsiņš Freivalds not knowing at that time that it was him. All he said to me after that meeting was that he was impressed with an ability to lead conversation in English by somebody who never had a chance to be abroad or to attend any international conferences.

Our next meeting was again under strange circumstances - on a bus in Latgale, region of Latvia. It was May 1980 and Soviet Union, of which Latvia was then a part, celebrated the 35th anniversary of the end of WWII. The University of Latvia track and field team (of which I was a part) proposed to perform a relay run from Zilupe (on Latvia's border with Russia where the Soviet Army first entered Latvia on July 18th, 1944) to Blīdene in the Kurzeme region of Latvia, about $500 \mathrm{~km}$. Since it was a highly politicized event, for each region the run was going through, there was assigned some senior member from the University of Latvia to be present. When I finished one of my parts of the relay and was getting onto our bus I was greeted by a man who said:

"You should stop running around, and should start serious work."

It was Rūsin̦š Freivalds. I replied, surprised:

"What do you mean by that?"

"You should focus on serious mathematics instead of wasting your time."

"Well, I tried, but it did not work." and I briefly explained to him my previous two failed attempts to start graduate work which had made me to think that I will never be able to do any mathematics research.

"You have potential; you should come to my seminars." He was brief and continued: "We are meeting every Tuesday afternoon at four thirty in the auditorium of university's Computing Center." 
The region he was in charge ended and he left us.

I graduated from University of Latvia cum laude as a mathematics and mathematics education major in 1977 and became mathematics instructor at the university, but knew nothing about what kind of research Freivalds and his group were doing. I knew nothing about Theoretical Computer Science. At that time, I was teaching calculus and geometry for physics undergraduates and prospective mathematics teachers, and was a part-time high school teacher myself, and had a part-time job on a grant about mathematical methods in nuclear physics.

After some hesitation I went to the first seminar, just to realize that having no background in computer science I could not understand a thing. I was ready to leave but Freivalds said that I should not do that after one meeting, that I should continue to come to seminars. He also required regular weekly meetings with him, so I could catch up on courses I missed as an undergraduate - algorithm theory, automata theory, etc.

Our meetings were held in his office - the room No. 419 he was sharing with three others. I still remember that room very clearly - three desks arranged parallel like in a classroom, Freivalds was sitting closer to the door, in front of him was the desk of Māris Alberts, and in front of the window was Agnis Andžāns' desk. Next to it in the corner was a file cabinet which was at the end of the desk positioned in front of the blackboard. That was a working space for Efim Kinber. During our meetings Freivalds usually explained a new notion, then assigned me about 4-5 problems, and I had a week to work on them. I am not sure that Rūsinšs even knew that in US such approach is called the Moore Method, neither did I. For me it was Freivalds' method of teaching computer science.

Soon after we started our meetings I had to leave for Moscow - in Fall 1980 I had to spend the semester in Moscow State University in a program meant for university instructors from all over the Soviet Union "to raise qualification". As it was with many mandatory things during Soviet times, one could spend this semester in Moscow just enjoying big city life. Not me - Freivalds required me to send him a list of offered courses and then made a list of classes I had to take. I remember classes by Vladimir Uspenskii and Alexei Semenov. Semenov took me to the famous Kolmogorov seminar. I also had a long reading list since being in Moscow I had a privilege to access Nauchno Technicheskaja Biblioteka (Library of Science and Technics) - in those days the only scientific library in the Soviet Union where I could read some mathematical journals. To lighten my fate, Freivalds also introduced me to Mathematical Intelligencer which was available in that library only. He himself often had business in Moscow those days because he was working on research for his habilitation dissertation. I was staying in a well-guarded graduate student dorm, and people there at the front desk became suspicious of me getting "photo telegrams" in some strange language with weird symbols - in those pre e-mail times that was the way for Freivalds to let me know what should I do next or that he will be in Moscow and we should meet in some metro station - he chose ones without transfers where we could not miss each other, and then we could talk on his way to Vnukovo airport where he was catching a flight back to Riga. Sometimes we met at Nauchno Technicheskaja Biblioteka. When I was meeting him in the lobby there for the first time he asked me where are the restrooms. It surprised me since I knew he had been there many times before but I pointed the direction anyway. When he turned to the opposite direction to go upstairs, seeing my amazement, he 
explained: "I do not need a restroom. This is my way of checking on whether students have been in the place before."

I was working on my $\mathrm{PhD}$ thesis parallel to my full time teaching job in the university. Several times I wanted to give up and quit but somehow Freivalds convinced me to continue even after long periods of me getting nowhere. Quite often I was stuck and terrified to go to meet Freivalds and tell him I do not know how to find the solution of the problem. To make me feel better about myself he would ask me to help him: I was the one he trusted to fill formulas by hand in his papers including his habilitation dissertation, because everything was typed by typewriter which did not have any mathematical symbols. I was also at his habilitation defense in Moscow in 1985 taking necessary notes, that is recording all questions asked and answers given for submitting to the habilitation board. Freivalds presented his work excellently, calm and confident, while I was taking notes with trembling fingers afraid not to make any mistake that could be used against him. He had told me various stories about mathematicians who had fallen out of favor for various reasons. I was thinking that he was being too cautious but in those days - who could know what can happen and why take a risk. Freivalds did not take even a risk to go to celebrate his big occasion by having a dinner in a restaurant. Because of regulations introduced by Andropov (General Secretary of the Communist Party of the Soviet Union) it was strictly forbidden to celebrate anything connected with one's work. Instead of having at least a cup of coffee anywhere "newly minted doctor" Freivalds chaperoned me to the place I was staying (with "Aunt Katya", former Bolshoi Theater ballet teacher whom I knew for many years). I invited Freivalds to have a dinner with us - pelmeni (Russian meat dumplings) and dessert from frozen strawberries I had made earlier - real surprise for both of us then to have a taste of fresh strawberries in the middle of the winter. After the dinner Freivalds enjoyed talking with Katya about Russian culture and history about which he had a good knowledge, until "Aunt Katya" noticed how tired we both were and told us that it is time to quit.

My own $\mathrm{PhD}$ thesis defense was quite dramatic. The first draft was completed just before my oldest daughter was born in 1987. However, it took almost three years to find an institution where I could defend my thesis. It was the time the Soviet Union was falling apart and most institutions along with it. It took a lot of effort and knowledge to navigate through all the formalities and obscure obstacles, and Freivalds was absolutely marvelous in doing that. When finally, my thesis defense was set for June 22, 1990 in Academy of Science of Belorussia in Minsk (there was no possibility to have $\mathrm{PhD}$ thesis in mathematics defended in Latvia at that time) and everything was arranged, the unexpected happened. It was two days before the big date when Freivalds called my main examiner (opponent), a star mathematician, to remind him about the defense and the star said he does not feel like travelling since he just returned from Paris and suggested to postpone the defense till fall, which was not an option for me, sixth month pregnant with my second child. It was a miracle how Freivalds at the last moment found a solution and the date was not postponed. I had to arrive in Minsk earlier and type necessary papers ahead of time by myself. I was using a record from the previous year when another Freivalds' graduate student defended his thesis at the same institution. I noticed that at the end of his defense my predecessor thanked everybody except his adviser. I was puzzled about that, but since Freivalds had so many times taught me how to follow strange rules, I decided that this is one of them - not to mention thesis adviser after a defense in the Academy of Sciences in Belorussia. When we were leaving the Academy Freivalds noted: "You are my second graduate student who did not thank me." 
I was devastated, and profoundly apologized explaining why it happened and that I am immensely grateful to him for all those ten years I was his student. Freivalds just smiled and told me not to worry about it. My chance to apologize publicly to him and thank him for all he has done for me came after 13 years when Freivalds received Grand Medal of Academy of Sciences of Latvia.

Up to the day of my PhD thesis defense I had never used $t u$ (familiar form of 'you' in Latvian) talking to Freivalds, it had always been $j \bar{u} s$ (formal 'you'). After I had received my $\mathrm{PhD}$ diploma Freivalds said: "Maybe now you can finally drop that formality and call me Rūsinšs like all my other students do?" Still it took me some time to get used to being less formal with my adviser.

I left Riga in 1996 but we kept e-mail contact, we had meetings when I was in Riga, and he visited Ithaca several times. Over the years our student-adviser relationship changed into close friendship. Rūsinšs could be more open with me about various issues I think exactly because I was away from Latvia. Several times he came to Ithaca with a group of his students whom he was taking around US to visit university campuses and to present their results in conferences. In summer 2005 Freivalds came to Ithaca alone, without students. He was a visiting researcher at Cornell University and stayed with us. Every morning he would go to his office to be there promptly by 9 am and would work there until 4 or $5 \mathrm{pm}$. Only after that could David (my husband) and I take Rūsinš for sightseeing or simply to the lake. He was not a swimmer but enjoyed to be in nature. Freivalds told me that the summer in Cornell was very valuable for him - the opportunity to do what he loved most of all - to do mathematics without any distractions and to attain some new results.

When on January $4^{\text {th }}$ of this year I received an e-mail with one short line "Your adviser Prof. Freivalds died." I could not believe it. I thought it was a mistake. It was just recently when we exchanged e-mails: I sent him birthday wishes; he wrote me that he is in Paris on his way back to Riga from Canada. That was Thursday, and the next day was a terror act in Paris, and I wrote to him: "I hope you are safe, and not in Paris anymore." He answered: "still in Paris, but safe". Just a week earlier Academia.org sent me a message that Rūsiņš Freivalds has marked me as a co-author on one of our joint papers, and I was asked to accept that. I knew he was working.

Rūsinš was very happy when his work was acknowledged, not that he would have lack of that. I think it was mostly because he was trying to prove that his mind is still full with new ideas, that the age had not slowed him down. Research Gate counts 214 publications for Freivalds. Rūsinšs once told me that he would like to reach 200, so he did it. I was arguing with him that instead of those numerous short publications and his numerous results scattered all over the place, he should write a monograph. He said the time will come and he will. Now it is left for his students and colleagues to gather his life's work together. I believe it will be done. However, there is no number or algorithm to measure the lasting imprints on his students and colleagues of his personality, generosity, care, attention, guidance, and kindness. 